\title{
Perbandingan Sistem Pengawasan Lembaga Antikorupsi Di Asia Pasifik
}

\author{
Nafiatul Munawaroh \\ Magister Hukum Fakultas Hukum Universitas Islam Indonesia Yogyakarta Indonesia \\ Jln. Cik Di Tiro No. 1 Yogyakarta Indonesia \\ nafimun@gmail.com
}

\begin{abstract}
This study discusses the comparison of the monitoring system of anti-corruption institutions in AsiaPacific countries, including Indonesia, Hong Kong, Malaysia, Myanmar, and Singapore. Through this comparative study, it is hoped that there will be a more proportional formulation of a supervisory system for anti-corruption institutions, especially in Indonesia. This study uses a normative juridical legal research method with a comparative approach. The legal materials used are primary and secondary legal materials obtained through literature studies and analyzed in a normative juridical manner. This study concludes that the comparative analysis of the anti-corruption agency supervisory system in Asia-Pacific, there are three trends. Low supervision system (laden with intervention) with low political will like Myanmar, proportional supervision but relatively low political will - both like Indonesia and Malaysia, and classic monitoring system (by executive, legislative and internal) but high political will like Hong Kong and Singapore.
\end{abstract}

Key Words: Anti-corruption institution; supervision; supervisory board

\begin{abstract}
Abstrak
Penelitian ini membahas mengenai perbandingan sistem pengawasan lembaga anti korupsi di negara-negara Asia Pasifik, di antaranya Indonesia, Hong Kong, Malaysia, Myanmar, dan Singapura. Melalui studi perbandingan ini diharapkan akan ada formulasi sistem pengawasan terhadap lembaga anti korupsi yang lebih proporsional terutama di Indonesia. Penelitian ini menggunakan metode penelitian hukum yuridis normatif dengan pendekatan perbandingan (comparative approach). Bahan hukum yang digunakan adalah bahan hukum primer dan sekunder yang diperoleh melalui studi pustaka dan dianalisis secara yuridis normatif. Penelitian ini menyimpulkan, bahwa analisis perbandingan sistem pengawasan lembaga anti-korupsi di Asia-Pasifik, terdapat tiga kecenderungan. Sistem pengawasan rendah (sarat intervensi) dengan political will rendah seperti Myanmar, pengawasan yang proporsional namun political will relatif rendah - baik seperti Indonesia, dan Malaysia, dan sistem pengawasan klasik (oleh eksekutif, legislatif dan internal) namun political will tinggi seperti Hong Kong dan Singapura.
\end{abstract}

Kata-kata Kunci: Lembaga anti-korupsi; pengawasan; dewan pengawas 


\section{Pendahuluan}

Eksistensi lembaga pemberantasan korupsi menjadi salah satu alternatif yang dipilih beberapa negara, termasuk Indonesia, untuk mewujudkan penyelenggaraan negara yang bersih dari berbagai bentuk perilaku koruptif. Lembaga pemberantasan korupsi di Indonesia sejatinya dijalankan oleh tiga lembaga, yaitu Kepolisian, Kejaksaan dan Komisi Pemberantasan Korupsi (KPK), dengan kewenangan yang berbeda. Dari ketiga lembaga tersebut, KPK ditunjuk sebagai lembaga yang mempunyai tugas utama dalam melaksanakan pencegahan, penyelidikan, penyidikan, penuntutan, supervisi, dan monitoring.

Kinerja KPK dalam menangani kasus korupsi dapat terlihat dari skor Indeks Persepsi Korupsi (IPK) Indonesia yang menurut Transparency International dari 2002 - 2018 dari $1.9^{1}$ naik menjadi 3.8. ${ }^{2}$ Kenaikan skor IPK di Indonesia tersebut menunjukkan bahwa Indonesia dalam pemberantasan korupsi terus mengalami kemajuan. Menurut laporan Transparency International, selama kurun waktu 2015 - 2019, kinerja KPK mendapat persentase sebesar 80\%. ${ }^{3}$ Prestasi tersebut salah satunya ditandai dengan meningkanya penindakan kasus korupsi yang diukur dari jumlah kerugian negara dari Rp. 1.400.000.000.000,00 pada 2016 menjadi Rp. 6.500.000.000.000,00 pada 2017.4

Prestasi KPK dalam pemberantasan korupsi tidak lantas lepas dari berbagai kritik. Secara kelembagaan, KPK seringkali dianggap sebagai superbody yang rawan terhadap penyalahgunaan wewenang. Kewenangan KPK yang besar terhadap pemberantasan korupsi mendorong lembaga legislatif untuk membenahi kelembagaan KPK, terutama dalam bidang pengawasan. Sistem pengawasan, sebaiknya memang dibangun secara proporsional untuk mencegah adanya kekuasaan yang absolut.

Pada 2019, melalui revisi UU KPK No. 19 Tahun 2019, dilakukan perubahan fundamental dalam bidang kelembagaan dan pengawasan KPK. Pasal 1 angka 3 disebutkan bahwa KPK merupakan lembaga negara dalam rumpun kekuasaan eksekutif yang melakukan tugas pencegahan dan pemberantasan korupsi.

1 Corruption Perception Index 2002: Results https://www.transparency.org/research/cpi/cpi 2002/0 diakses pada 8 Oktober 2019.

2 Corruption Perception Index 2018 https://www.transparency.org/cpi2018 diakses pada 8 Oktober 2019. Di dalam laman Transparency International penulisan Indeks Persepsi Korupsi pada 2002, menggunakan angka pecahan. Sedangkan pada 2018, Indeks Persepsi Korupsi tidak lagi ditulis menggunakan angka pecahan. Untuk Indonesia, Indeks Persepsi Korupsi ditulis 38, bukan 3.8. Penulis menyantumkan angka pecahan agar lebih mudah menganalisa perbandingan angka Indeks Persepsi Korupsi dari awal KPK dibentuk hingga 2018.

3 Wawan Suyatmiko, Alvin Nicola, "Inisiatif Penguatan Lembaga Antikorupsi Indonesia: Komisi Pemberantasan Korupsi 2015 - 2019”, Transparency International 2019, hlm. 8

${ }^{4}$ Tempo, 2017 yang dikutip Ibid., hlm. 14 
Sebelumnya, dalam UU KPK No. 30 Tahun 2002, KPK merupakan lembaga negara yang bersifat independen, bebas dari kekuasaan manapun.

Perubahan mendasar selanjutnya yaitu pembentukan Dewan Pengawas. Keberadaan Dewan Pengawas dalam revisi UU KPK dinilai berbagai kalangan sebagai bentuk pengekangan terhadap independensi KPK karena mempunyai kewenangan yang besar, dari mulai izin penyadapan hingga menegakkan etik. Bagaimana sebaiknya pengawasan yang proporsional terhadap lembaga antikorupsi?

Studi atas sistem pengawasan dari lembaga anti-korupsi berbagai negara perlu dilakukan untuk memberikan gambaran perumusan sistem pengawasan yang proporsional. Artikel ini akan memberikan perbandingan sistem pengawasan lembaga pemberantasan korupsi di beberapa negara Asia-Pasifik. Tipe-tipe lembaga pemberantasan korupsi di Asia Pasifik menurut TI dibagi menjadi dua, yaitu tipe A dan tipe B. Tipe A adalah lembaga yang lebih efektif karena fokus menangani fungsi anti-korupsi saja. Sedangkan tipe B, merupakan lembaga yang kurang efektif melaksanakan anti-korupsi karena menjalankan dua fungsi sekaligus, yaitu fungsi anti-korupsi dan fungsi yang tidak terkait dengan korupsi. ${ }^{5}$ Dalam artikel ini perbandingan lembaga anti-korupsi mengacu pada tipe A, yang fokus dalam penanganan anti-korupsi saja. Di antaranya Indonesia, Myanmar, Malaysia Singapura dan Hong Kong. ${ }^{6}$

Perbandingan tersebut bertujuan untuk memberikan gambaran bagaimana negara-negara yang mempunyai lembaga pemberantasan korupsi yang independen menjalankan fungsinya serta mekanisme pengawasannya. Hasil dari analisis tersebut akan menjadi bahan kajian dan masukan terhadap sistem pengawasan yang perlu (atau tidak perlu) dibangun untuk KPK.

\section{Rumusan Masalah}

Bagaimanakah perbandingan sistem pengawasan lembaga anti-korupsi di berbagai negara di Asia Pasifik dalam rangka pembentukan sistem pengawasan yang proporsional?

5 Jon S.T. Quah, "Anti-Corruption Agencies in Asia Pacific Countries: An Evaluation of their Performance and Challenges", Transparency International 2017, diakses melalui https://www.transparency.org/ files/content/feature/2017 ACA Background Paper.pdf tanggal 9 Oktober 2019, hlm. 3

${ }^{6}$ Ibid., hlm. 31 


\section{Tujuan Penelitian}

Menganalisis perbandingan sistem pengawasan lembaga anti-korupsi di negara-negara Asia Pasifik sebagai gambaran pembentukan sistem pengawasan yang proporsional.

\section{Metode Penelitian}

Penelitian hukum normatif adalah penelitian hukum yang meletakkan hukum sebagai sebuah bangunan sistem norma. Sistem norma yang dimaksud adalah mengenai asas-asas, norma, kaidah dari peraturan perundang-undangan, putusan pengadilan, perjanjian serta doktrin (ajaran). ${ }^{7}$ Penelitian ini menggunakan pendekatan perbandingan (comparative approach). Penelitian ini menggunakan bahan hukum primer dan bahan hukum skunder. Bahan hukum primer terdiri dari peraturan perundang-undangan, yakni UU No. 19 Tahun 2019 tentang Perubahan Kedua atas Undang-Undang Nomor 30 Tahun 2002 tentang Komisi Pemberantasan Tindak Pidana Korupsi, maupun peraturan-peraturan yang terkait baik dari Indonesia maupun negara-negara Asia Pasifik lainnya yang relevan. Bahan hukum skunder terdiri atas buku, jurnal ataupun penelitian yang sesuai dengan tema pembahasan.

Metode analisis bahan hukum yang dipergunakan dalam penelitian ini adalah deskriptif kualitatif yaitu pengelompokan dan penyelesaian data-data yang diperoleh dari suatu gambaran sistematis yang didasarkan pada teori dan pengertian hukum yang terdapat dalam ilmu hukum untuk mendapatkan kesimpulan yang ilmiah. ${ }^{8}$

\section{Hasil Penelitian dan Pembahasan}

\section{Negara-negara ASEAN}

\section{Indonesia}

KPK Republik Indonesia dibentuk melalui UU No. 30 Tahun 2002 dan resmi berdiri pada tahun 2003. Pembentukan KPK ini dilatarbelakangi atas tuntutan reformasi berupa pemberantasan korupsi serta tidak maksimalnya peran Kejaksaan dan Kepolisian dalam penanganan kasus korupsi. KPK dibentuk sebagai lembaga independen yang mempunyai kewenangan pencegahan dan penindakan korupsi yang cukup besar, dibanding kepolisian dan kejaksaan.

7 Mukti Fajar \& Yulianto Achmad, Dualisme Penelitian Hukum Normatif \& Empiris, Pustaka Pelajar, Yogyakarta, 2013, hlm. 34.

8 Burhan Bungin, Metodologi Penelitian Kualitatif: Komunikasi, Ekonomi, dan Kebijakan Publik serta Ilmu-ilmu Sosial Lainnya, Prenada Media Group, Jakarta, 2010, hlm. 150. 
Susunan struktur KPK RI terdiri atas lima Pimpinan KPK, tim penasihat yang terdiri dari empat anggota dan pegawai KPK. ${ }^{9}$

Sistem pengawasan yang dibangun untuk KPK dalam UU No. Tahun 2002 dapat dilihat di dalam Pasal 20, bahwa KPK bertanggung jawab kepada publik atas pelaksanaan tugasnya dan menyampaikan laporannya secara terbuka dan berkala kepada Presiden, DPR dan BPK. Pertanggungjawaban publik yang dimaksud berupa wajib audit terhadap kinerja dan pertanggungjawaban sesuai dengan program kerja, menerbitkan laporan tahunan serta membuka akses informasi. Pertanggungjawaban KPK yang langsung kepada publik, bukan bertanggung jawab kepada DPR, Presiden maupun lembaga lainnya, merupakan wujud sistem pengawasan yang akuntabilitas lembaga negara yang demokratis. Artinya, publik mempunyai kekuatan besar dalam mengontrol langsung KPK. Selain itu, pemberian laporan kepada DPR dan Presiden merupakan bentuk check and balances antar lembaga negara yang berjalan secara proporsional.

Sistem pengawasan KPK kemudian diubah di dalam revisi UU KPK, yang tidak hanya dilakukan oleh publik, DPR maupun Presiden, namun juga dilakukan oleh Dewan Pengawas. Keberadaan Dewan Pengawas dalam Revisi UU KPK sejatinya menggantikan posisi tim penasihat yang ada di dalam UU KPK No. 30 Tahun 2002. Tim Penasihat mempunyai fungsi utama, menurut Pasal 23 UU KPK No. 30 Tahun 2002 yaitu memberikan nasihat dan pertimbangan sesuai dengan kepakarannya kepada KPK dalam pelaksanaan tugas dan wewenang KPK. Melalui revisi UU KPK, tim penasihat yang kemudian dihapus dan diganti menjadi Dewan Pengawas dengan kewenangan dasar yaitu memberikan (atau tidak memberikan) izin tertulis penyadapan yang dimintakan oleh Pimpinan $\mathrm{KPK}, 10$ penggeledahan, dan/atau penyitaan, ${ }^{11}$, menyusun dan menetapkan kode etik pimpinan dan Pegawai KPK, ${ }^{12}$ menerima, menindaklanjuti dan menyelenggarakan sidang atas laporan masyarakat atas dugaan pelanggaran kode etik pimpinan dan pegawai $\mathrm{KPK}^{13}$ serta melakukan evaluasi kinerja pimpinan dan pegawai KPK. ${ }^{14}$

\footnotetext{
${ }^{9}$ Lihat Pasal 21 UU No. 30 Tahun 2002

10 Pasal 12B ayat (1) "Penyadapan sebagaimana dimaksud Pasal 12 ayat (1) dilaksanakan setelah mendapatkan izin tertulis dari Dewan Pengawas". Ayat (2) "Untuk mendapatkan izin sebagaimana dimaksud pada ayat (1) dilaksanakan berdasarkan permintaan secara tertulis dari Pimpinan Komisi Pemberantasan Korupsi”.

${ }^{11}$ Pasal 37B ayat (1) huruf b "memberikan izin atau tidak memberikan izin Penyadapan, penggeledahan, dan/atau penyitaan.

12 Pasal 37B ayat (1) huruf c Ibid

13 Pasal 37B ayat (1) huruf d dan e Ibid

14 Pasal 37B ayat (1) huruf f Ibid
} 
Dewan Pengawas terdiri dari lima orang untuk maksimal dua kali masa jabatan. ${ }^{15}$ Dewan Pengawas melaporkan kinerjanya secara berkala yakni dalam kurun satu tahun kepada Presiden dan DPR.16 Ketua dan anggota Dewan Pengawas diangkat dan ditetapkan oleh Presiden melalui panitia seleksi. Daftar nama calon Dewan Pengawas dikonsultasikan kepada DPR dan akhirnya ditetapkan Presiden. ${ }^{17}$

Dilihat dari political will perumusan Dewan Pengawas KPK, pembentukannya terkesan buru-buru. Revisi UU KPK tidak masuk ke dalam program legislasi nasional (prolegnas) 2019, dan hanya masuk di dalam prolegnas 2015 dan 2016. Akan tetapi, secara tiba-tiba revisi UU KPK masuk dan disahkan di dalam prolegnas 2019. Di dalam draft revisi UU KPK tahun 2016, struktur kelembagaan KPK tidak didapati adanya Dewan Pengawas dan tidak mengubah KPK dari lembaga independen menjadi lembaga bagian dari eksekutif. Selain itu, struktur Dewan Pengawas serta proses pengangkatannya dilakukan oleh eksekutif. Dengan kewenangan yang besar, keberadaan Dewan Pengawas yang "berorientasi" pada lembaga eksekutif dan lembaga KPK yang diubah menjadi rumpun eksekutif, bukan lagi memberikan check and balances yang proporsional, justru mengekang independensi KPK. Hal ini tentu saja tidak sejalan dengan ide lembaga-lembaga penunjang independen, yang seharusnya tidak terkooptasi oleh kekuasaan eksekutif maupun legislatif. ${ }^{18}$

\section{Myanmar}

Negara Myanmar adalah salah satu negara di kawasan Asia Tenggara yang memiliki sejarah cukup mirip dengan Indonesia. Reformasi Myanmar yang ditandari lepasnya rezim junta militer, Myanmar berkomitmen dalam pemberantasan korupsi untuk penyelenggaraan negara yang lebih bersih. Di 2012 sampai 2018, hanya selama enam tahun, Myanmar mampu meningkatkan skor IPK-nya sebesar 14 poin, dari angka 15 menjadi 29.19 Meskipun skor tersebut masih berada di bawah Indonesia, namun angka yang cukup signifikan selama enam tahun tersebut menunjukkan komitmen Myanmar terhadap pemberantasan korupsi cukup tinggi.

Manifestasi komitmen pemberantasan korupsi di Myanmar adalah membentuk Anti-Corruption Commission (ACC) didirikan 2014 yang berwenang

${ }^{15}$ Lihat Pasal 37A ayat (2) dan (3) UU No. 19 Tahun 2019

${ }^{16}$ Lihat Pasal 37B ayat (2) dan (3) Ibid

${ }^{17}$ Lihat Pasal 37E Ibid

18 Hendra Nurtjahjo, "Lembaga, Badan, dan Komisi Negara Independen (State Auxiliary Agencies) di Indonesia: Tinjauan Hukum Tata Negara”, Jurnal Hukum dan Pembangunan Vol. 35 No. 3 Juli-September 2005, hlm. 280

19 Corruption Perception Index 2018: Statistically Significant Changes https://www.transparency.org/cpi2018 diakses pada 8 Oktober 2019 
untuk menginvestigasi korupsi, mengusut pelanggaran atas UU 2013 dan memberikan rekomendasi dalam memberantas korupsi, serta mempunyai kewenangan untuk meminta bantuan dari organisasi Internasional. ${ }^{20}$

ACC terdiri dari 15 anggota, 5 diantaranya dipilih oleh Presiden, 5 dari lower house dan 5 dari upper house. ${ }^{21}$ Komisi bertanggung jawab kepada presiden.22 Dalam hal ini, kedudukan tertinggi dalam struktur kelembagaan ACC adalah komisi/komisioner. Struktur lembaga ACC terdiri dari investigation board, preliminary scrutiny board, working committees, working group, inspector-general dan inspectors yang dibentuk oleh Komisi. ${ }^{23}$ Dalam hal struktur ACC, Presiden dapat menentukan atau mengubah anggota dari Preliminary Scrutiny Board dan Investigation Board.24

Pengawasan terhadap ACC dilakukan langsung oleh Presiden bersama dengan lower house dan upper house. Salah satunya melalui pemberhentian komisi jika komisi dalam menjalankan kewajibannya bertentangan dengan hukum atau melanggar konstitusi Myanmar atau hukum yang berlaku maupun jika terdapat tindakan yang menodai citra Komisi, dengan mendapatkan persetujuan dari pihak yang memilih anggota yang bersangkutan. ${ }^{25}$ Artinya, jika anggota komisi yang bersangkutan dipilih oleh upper house, maka dalam proses pemberhentiannya, Presiden meminta persetujuan dari upper house. Presiden dan parlemen bahkan bisa mengintervensi proses investigasi dengan memberikan tugas investigasi terhadap seseorang kepada $\mathrm{ACC}^{26}$ dan meminta laporan atas investigasinya. ${ }^{27}$

Sistem pengawasan yang dibangun oleh Myanmar cenderung memberikan peran yang besar kepada lembaga eksekutif dan legislatif dalam penyelenggaraan ACC. Sehingga, ACC secara politis posisinya sangat lemah sehingga sampai 2017, dari 4500 kasus korupsi yang masuk, hanya dilakukan investigasi sebanyak 66 kasus. Sedangkan 1000 kasus diantaranya diproses oleh kementerian untuk dilakukan investigasi internal. ${ }^{28}$

Political will Myanmar dalam pemberantasan korupsi - meskipun telah mengalami peningkatan - masih terbilang rendah. Sebagai negara transisi, junta

${ }^{20}$ Mathias Bak, "Overview of Corruption and Anti-Corruption in Myanmar", Transparency International Helpdesk Answer, 2019, hlm. 15

21 ibid.

22 Lihat Chapter III Article 7(b) The Anti-Corruption Law (The Pyidaungsu Law No. 3, 2013) Myanmar.

${ }^{23}$ Lihat Chapter II Article 3 (a), (c) The Anti-Corruption Commission Notification No. 3/2015 Myanmar

${ }^{24}$ Lihat Chapter III Article 14 The Anti-Corruption Law (The Pyidaungsu Law No. 3, 2013) Myanmar.

${ }^{25}$ Lihat Chapter III Article 15 The Anti-Corruption Law (The Pyidaungsu Law No. 3, 2013) Myanmar.

${ }^{26}$ Lihat Chapter V Article 21 (a) (b) dan No. 43 The Anti-Corruption Law (The Pyidaungsu Law No. 3, 2013) Myanmar.

${ }^{27}$ Lihat Chapter V Article 30 The Anti-Corruption Law (The Pyidaungsu Law No. 3, 2013) Myanmar.

${ }^{28}$ Ibid., hlm. 15 
militer Myanmar masih mendominasi dalam penyelenggaraan negara, seperti proporsi kursi di parlemen yang dipesan militer sangat besar, kontrol terhadap pertahanan, batas dan kementerian-kementerian, serta mengontrol posisi-posisi penting di birokrasi. ${ }^{29}$ Isu keamanan dan pengmbangunan, konflik antar etnis serta identitas nasional ${ }^{30}$ juga merupakan faktor politis yang menghambat kerjakerja ACC dalam pemberantasan korupsi.

\section{Malaysia}

Malaysia merupakan salah satu negara ASEAN yang skor IPK-nya tidak jauh berbeda dengan Indonesia. Sejarah upaya pemberantasan korupsi di Malaysia sebenarnya telah dimulai dari kolonialisme Inggris melalui beberapa peraturan seperti Penal Code 1871. Kemudian, Malaysia memformulasikan institusi untuk menangani korupsi, dari 1967 berupa Anti-Corruption Agency (ACA), Public Complaints Bureau (PCB), Auditor General's Office, Public Account Committee, Polisi, Attorney General's Office, Customs and Malaysian Administration Modernization and Management Planning Unit (MAMPU). ${ }^{31}$ Pada tahun 2004 pemerintahan Abdullah Ahmad Badawi kemudian dibentuk National Integrity Plan (NIP) yang bertujuan mempromosikan integritas dan etik di masyarakat. Bersamaan dengan NIP dibentuk Malaysian Institute Integrity (MII) yang dibentuk untuk mendorong efektifitas koordinasi dan implementasi NIP. ${ }^{32}$ Lembaga terakhir dan mungkin paling signifikan yakni Malaysian Anti-Corruption Commission (MACC). ${ }^{33}$

Pembentukan MACC didasarkan pada Act 694 tentang Malaysian AntiCorruption Commission Act 2009. Struktur MACC yakni Ketua Komisioner, pegawai Komisi, Dewan Penasihat Anti-Korupsi (Anti-Corruption Advisory Board), Komite Spesial Korupsi (Special Committee on Corruption) dan Komite Pengaduan (Complaints Committee). Ketua komisioner ditunjuk oleh Yang Dipertuan Agong dengan saran dari Perdana Menteri. ${ }^{34}$ Ketua Komisioner bertanggungjawab untuk memberikan arahan, kontrol dan sipervisi atas segala hal yang menyangkut komisi. $^{35}$

MACC dalam menjalankan kewenangannya didampingi oleh Dewan Penasihat yang terdiri dari tujuh anggota salah satunya Ketua Komisioner sebagai

\footnotetext{
${ }^{29}$ Ibid., hlm. 2

${ }^{30}$ Ibid.

31 Nur Shafiqa Kapeli and Nafsiah Mohamed, "Insight of Anti-Corruption Initiatives in Malaysia", Procedia Economics and Finance (31) 2015, hlm. 527

32 Noore Alam Siddiquee, "Approaches to Fighting Corruption and Managing Integrity in Malaysia: A Critical Perspective”, Journal of Administrative Science Vol. 8 Issue I, 2011, hlm. 56

33 Ibid, hlm. 57

${ }^{34}$ Lihat Part II Article 5 (1) Act 694 tentang Malaysian Anti-Corruption Commission Act 2009

35 Lihat Part II Article 5 (5) Ibid
} 
ex-officio, ditunjuk oleh Yang Dipertuan Agong. ${ }^{36}$ Berbeda dengan tim penasihat KPK, Dewan Penasihat MACC mempunyai beberapa fungsi diantaranya: ${ }^{37}$

a. memberikan saran kepada Komisi dalam berbagai aspek permasalahan korupsi di Malaysia;

b. memberikan saran kepada Komisi mengenai kebijakan dan strategi bagi Komisi dalam Pemberantasan Korupsi;

c. menerima, meneliti dan mendorong kebutuhan sumber daya Komisi untuk memastikan efektifitasnya;

d. meneliti laporan tahunan Komisi sebelum diserahkan kepada Special Committee of Corruption; dan

e. Menyerahkan komentar laporan tahunan kepada Special Committee of Corruption khusus untuk pelaksanaan fungsi Komisi di bawah undangundang ini.

Pengawasan terhadap MACC dilaksanakan oleh Special Committee on Corruption (SCC) dan Complaints Committee (CC). SCC dan CC dapat dikatakan sebagai pengawas internal MACC. 38 SCC terdiri dari 7 anggota ditunjuk oleh Yang Dipertuan Agong yang merupakan anggota Senat dan House of Representative. SCC mempunyai fungsi untuk memeriksa laporan tahunan komisi berserta komentarnya dari Dewan Penasihat dan mengklarifikasi serta meminta penjelasan atas laporan tahunan tersebut. SCC memberikan laporan tahunan atas fungsinya kepada Perdana Menteri dan Parlemen. ${ }^{39}$

CC berfungsi untuk memantau penanganan oleh Komisi atas pengaduan pelanggaran non-kriminal yang dilakukan oleh pegawai Komisi serta mengidentifikasi kelemahan prosedur kerja Komisi yang dapat menyebabkan aduan dan jika dianggap layak membuat rekomendasi seperti prosedur kerja Komisi yang menurutnya sesuai. ${ }^{40}$ Anggota CC ditunjuk oleh Menteri yang bertanggungjawab terhadap MACC. ${ }^{41}$

Political will pemerintah Malaysia dalam pemberantasan korupsi sebenarnya masih terbilang rendah. Hal ini terlihat dari kecenderungan Malaysia untuk membentuk institusi anti-korupsi baru, alih-alih menguatkan yang ada. Kepemimpinan di Malaysia efektif dalam mengadopsi model baru dengan bungkus dan jargonnya, namun rendah dalam efektifitas implementasinya. ${ }^{42}$ Menurut hemat penulis, didirikannya MACC dengan sistem yang baru,

\footnotetext{
${ }^{36}$ Lihat Part III Article 13 (1), (2), (3) Ibid

${ }^{37}$ Lihat Part III Article 13 (5) Ibid

${ }^{38}$ Lihat Part III on Special Committee on Corruption dan Complaints Committee Article 14 dan 15 Ibid

${ }^{39}$ Lihat Part III on Special Committee on Corruption dan Complaints Committee Article. 14 Ibid

${ }^{40}$ Lihat Part III on Special Committee on Corruption dan Complaints Committee Article 15 Ibid

${ }^{41}$ Lihat Part III on Special Committee on Corruption dan Complaints Committee Article 15 dan Part I

${ }^{42}$ Noore Alam Siddiquee, Op. Cit., hlm. 67
} Article 3. Ibid 
menunjukkan political will Malaysia dalam pemberantasan korupsi cukup baik dimana pihak Monarki, eksekutif maupun parlemen tidak banyak intervensi dalam menjalankan aktivitas MACC.

\section{Singapura}

Singapura Corrupt Practices Investigation Bureau (CPIB) didirikan pada 1952. Sebagai lembaga tertua dalam bidang anti-korupsi, prestasi CPIB tidak diragukan lagi. Skor IPK Singapura berdasarkan Transparency International sejak 2012 - 2018 berada di dalam ranking 10 besar dunia dengan skor kisaran $84-87$. Terakhir, pada tahun 2018, Singapura menempati urutan ketiga dunia, dengan IPK $84 .{ }^{43}$

CPIB diatur di dalam Chapter 241 Ordinance 39 of 1960 on Prevention of Corruption Act 1960 meskipun telah didirikan pada 1952. CPIB berdasarkan Chapter 241 diberikan kewenangan penindakan seperti penangkapan, investigasi, memerintahkan pemeriksaan buku bankir (banker's book seperti buku kas dll), mengumpulkan informasi, dan penyitaaan. ${ }^{44}$ CPIB mempunyai kewenangan untuk melaksanakan investigasi terhadap korupsi di berbagai sektor, baik sektor publik maupun sektor swasta, termasuk pegawai negeri, militer, Peradilan, Parlemen serta bagian dari kegiatan industri dan bisnis. ${ }^{45}$ Kewenangan CPIB dalam pemberantasan korupsi di sektor publik dan swasta tersebut bertujuan untuk mewujudkan pemerintahan yang bersih dan memastikan aktivitas ekonomi yang sehat. ${ }^{46}$ Selain berwenang dalam penindakan, CPIB juga mempunyai fungsi dan wewenang dalam bidang pendidikan dan program pencegahan di sektor publik dan swasta. ${ }^{47}$

Direktur CPIB ditunjuk oleh Presiden, yang berasal dari pegawai CPIB. 48 Selain Direktur, Presiden juga menunjuk Deputi Direktur, Asisten Direktur dan investigator spesial. ${ }^{49}$ Menurut Soh Kee Hean, Direktur CPIB, CPIB berada di bawah Perdana Menteri dan memberikan laporan kepada Perdana Menteri. Independensi lembaga dapat terjaga karena tidak ada lembaga pemerintahan lain dapat mempengaruhi penegakan dan investigasi CPIB.50 Independesi CPIB diperkuat dengan amandemen Konstitusi Singapura pada 1991, Article 22G yang

\footnotetext{
Corruption Index Perception 2018: Score Timeseries Since 2012, https://www.transparency.org/cpi2018 diakses pada 8 Oktober 2019.

${ }^{44}$ Part IV Prevention of Corruption Act (Chapter 241) Ordinance 39 of 1960 Singapore

${ }^{45}$ Soh Kee Hean, "Investigation and Prosecution of Corruption Offences", Resource Material Series No. 80 The Twelfth International Training Course on the Criminal Justice Response to Corruption Cisiting Expert's Papers diakses melalui https://www.unafei.or.jp/publications/pdf/RS No80/No80 20VE Hean2.pdf pada 14 Oktober 2019, hlm. 158

${ }^{46}$ Ibid.

${ }^{47}$ Ibid., hlm. 97.

${ }^{48}$ Part II Article 3 (1) Ibid.

${ }^{49}$ Part II Article 3 (2) Ibid

${ }^{50}$ Soh Kee Hean, OpCit, hlm. 157
} 
memberikan kewenangan pada Direktur CPIB untuk menginvestigasi menteri dan birokrat senior tanpa harus mendapatkan persetujuan dari Perdana Menteri jika telah mendapatkan persetujuan dari Presiden Terpilih. Artinya, CPIB dapat menginvestigasi Perdana Menteri jika telah mendapatkan izin dari Presiden Terpilih. ${ }^{51}$

Sistem pengawasan yang dibangun CPIB tidak terlalu menonjol. Selain laporan kepada Perdana Menteri, di dalam internal lembaga CPIB terdapat internal audit untuk akuntabilitas dana publik. ${ }^{52}$ Menurut hemat penulis, sistem pengawasan yang 'tidak terlalu' ketat dari lembaga tertentu, menekankan independensi lembaga anti-korupsi dalam menjalankan fungsi dan wewenangnya. CPIB menekankan pada dukungan publik yang dianggap sebagai elemen vital dalam pemberantasan korupsi. Untuk meraih dukungan publik tersebut, CPIB membangun sistem yang aksesibel untuk publik seperti kemudahan publik untuk menyampaikan komplain. ${ }^{53}$

Singapura merupakan negara dengan political will yang tinggi dalam pemberantasan korupsi. Selain dukungan publik yang tinggi, sejak awal political will pemberantasan korupsi dibangun oleh Lee Kuan Yew pada 1959 ketika People's Action Parti (PAP) masuk ke pemerintahan. Misi PAP dari awal yakni membentuk pemerintahan yang meritokratik, tidak korup, dan memberantas korupsi dari berbagai level masyarakat. ${ }^{54}$

\section{Negara Asia Lainnya}

\section{Hong kong}

Hong Kong Independent Commission Against Corruption (ICAC) didirikan 1974. ICAC terdiri dari Komisioner, Deputi Komisioner, dan pegawai/pejabat (officer) yang ditunjuk. Komisioner dikontrol oleh Chief Executive dan bertanggungjawab untuk mengarahkan dan administrasi Komisi. ${ }^{55}$ Kelembagaan ICAC terdiri dari Komisioner, Deputi Komisioner dan Pegawai ICAC.56 Kewenangan yang dimiliki ICAC berkenaan dengan investigasi yaitu

51 Vincent Lim, “An Overview of Singapore's Anti-Corruption Strategy and The Role of the CPIB in Fighting Corruption”, Resource Material Series No. 104, 20th UNAFEI UNCAC Training Programme Cisiting Experts Papers, diakses melalui https://www.unafei.or.jp/publications/pdf/RS No104/No104 18 VE Lim 1.pdf pada 14 Oktober $2019 \mathrm{hlm} .96$

52 Diagram B, CPIB Organisational Structure dalam ibid.

${ }^{53}$ Ibid.

54 Soh Kee Hean, Op. Cit., hlm. 183

55 Article 5 (1) Cap. 204 Independent Commission Against Corruption Ordinance, Hong Kong

56 Article 5, 6, 8 Ibid 
penangkapan, penuntutan, pengejaran (search) dan penyitaan. ${ }^{57}$ Selain investigasi, ICAC juga mempunyai tugas dalam pencegahan dan pendidikan. ${ }^{58}$

Sistem pengawasan terhadap ICAC, salah satunya mengenai keuangan. Anggaran belanja ICAC diajukan kepada Chief Executive setiap awal tahun anggaran dan melaporkannya kepada Chief Executive di setiap akhir tahun anggaran. Dalam pengelolaan keuangannya, ICAC diaudit oleh Direktur Audit yang berwenang untuk mengakses akun ICAC serta dapat meminta informasi dan penjelasan atas pengelolaannya. ${ }^{59}$ Laporan tahunan ICAC diserahkan kepada Chief Executive di akhir tahun mengenai aktivitas ICAC dan oleh Chief Executive diteruskan kepada Legislative Council.60

Skor IPK Hong Kong dari $2012-2018^{61}$ yang tidak jauh dari 77 menempati urutan 20 besar dunia. Terakhir, tahun 2018, Hong Kong menempati posisi ke 13 dunia dalam pemberantasan korupsi. Prestasi pemberantasan korupsi ICAC ini didukung dengan kultur dan political will yang baik dari masyarakat dan pemerintah Hong Kong. Hong Kong mempunyai kultur zero tolerance of corruption dan mendukung penuh upaya pemberantasan korupsi, yang dibuktikan dengan Annual Survey 2013 yang mengungkapkan sebesar 80,7\% masyarakat menyatakan korupsi tidak dapat ditolerir. ${ }^{62}$ Selain itu, Hong Kong berhasil mengkondisikan pemerintahan yang bersih melalui investigasi korupsi ICAC serta promosi atas Code of Conduct serta Declaration of Conflict of Interest Guidelines yang diadopsi oleh berbagai departemen dalam pemerintahan. ${ }^{63}$

\section{Desain Sistem Pengawasan Lembaga Anti-Korupsi untuk Indonesia}

\begin{tabular}{llc}
\hline \multicolumn{1}{c}{ Negara } & \multicolumn{1}{c}{ Sistem Pengawasan } & Dukungan Political Will \\
\hline Indonesia & Publik, DPR, Presiden dan Dewan Pengawas & Relatif rendah \\
Myanmar & Presiden dan Parlemen & Rendah \\
Malaysia & SCC dan CC & Cukup baik \\
Singapura & Perdana Menteri, internal audit & Tinggi \\
Hong Kong & Chief Executive, Direktur Audit & Tinggi \\
\hline
\end{tabular}

57 Cap. 204 Independent Commission Against Corruption Ordinance, Hong

58 Thomas Chan, "Corruption Prevention - The Hong Kong Experience", Resource Material Series No. 56 113th International Training Course Visiting Experts Papers, hlm. 367

${ }^{59}$ Article 15 dan 16 Cap. 204 Independent Commission Against Corruption Ordinance, Hong

${ }^{60}$ Article 17 Ibid

${ }^{61}$ Corruption Index Perception 2018: Score Timeseries Since 2012 Op. Cit

${ }^{62}$ Hui Wing-Chi, "Combating Corruption: The Hong Kong Experience”, Tsinghua China Law Review Vol. 6: 239 2014, hlm. 249

${ }^{63}$ Ibid., hlm. $249-250$ 
Berdasarkan perbandingan tersebut, maka dapat dilihat tiga kecenderungan sistem pengawasan lembaga anti-korupsi di Asia-Pasifik. Sistem pengawasan rendah (sarat intervensi) dengan political will rendah seperti Myanmar, pengawasan yang proporsional namun political will relatif rendah - baik seperti Indonesia, dan Malaysia, dan sistem pengawasan klasik (oleh eksekutif, legislatif dan internal) namun political will tinggi seperti Hong Kong dan Singapura. Dalam hal ini, Indonesia dengan political will yang relatif lebih rendah, tidak mengambil sistem pengawasan klasik seperti menempatkan KPK di bawah rumpun eksekutif dan melibatkan eksekutif dalam pengawasan terlalu tinggi. Hal ini dikhawatirkan akan mencontoh Myanmar dimana intervensi parlemen dan eksekutif tinggi, sehingga pemberantasan korupsi menjadi tidak maksimal. Jika akan mengadopsi Dewan Pengawas sebaiknya menyontoh SCC dan CC Malaysia yang tidak mencampuri proses investigasi korupsi. Hal ini untuk menjaga independensi lembaga sebagai salah satu indikator pemberantasan korupsi yang baik menurut TI. 64

Selain faktor-faktor di atas, jika merujuk pada konsep KPK sebagai komisi negara yang berperan penting dalam penegakan hukum di bidang pemberantasan korupsi, maka independensi lembaganya harus tetap dijaga. Contoh di Amerika Serikat yang cukup relevan adalah konsep independent agencies yang merupakan organ utama di luar eksekutif. ${ }^{65}$ Sifat agensi independen ini yaitu pertama, bukan merupakan bagian dari executive department atau kementerian, legislatif ataupun yudikatif; kedua diatur secara tegas di dalam undang-undang yang membentuknya bahwasannya pengawasan lembaga tersebut tidak melekat pada Presiden; ketiga, kedudukan dan kewenangannya berasal dari undang-undang; keempat kepemimpinan kolektif, tidak dikuasai dari partai tertentu, dan masa jabatan pimpinan habis secara bergantian; dan kelima tidak terdapat pertanggungjawaban. ${ }^{66}$ Untuk membentuk lembaga negara seperti KPK agar fungsinya maksimal, maka selain political will dan pengawasan internal maupun eksternal yang baik, juga penguatan kelembagaan KPK yang independen. Independensi ini berupa KPK tidak menjadi bagian dari eksekutif ataupun cabang kekuasaan lain.

\section{Penutup}

Berdasarkan analisis perbandingan sistem pengawasan lembaga antikorupsi di Asia-Pasifik, maka terdapat tiga kecenderungan. Sistem pengawasan

${ }^{64}$ Jon S.T. Quah, Op. Cit., hlm. 52

${ }^{65}$ Isharyanto, Hukum Kelembagaan Negara (Studi Hukum dan Konstitusi Mengenai Perkembangan Ketatanegaraan Republik Indonesia), Cetakan I, Fakultas Hukum UNS, Surakarta, 2015, hlm. 208

${ }^{66}$ Ibid., hlm. 208 - 209 
rendah (sarat intervensi) dengan political will rendah seperti Myanmar, pengawasan yang proporsional, namun political will relatif rendah - baik seperti Indonesia, dan Malaysia, dan sistem pengawasan klasik (oleh eksekutif, legislatif dan internal) namun political will tinggi seperti Hong Kong dan Singapura. Indonesia sebaiknya tidak mengambil alternatif pengawasan klasik dengan political will yang rendah dengan menjadikan KPK sebagai rumpun eksekutif maupun memberikan ruang bagi eksekutif dalam mengintervensi kelembagaan KPK. Selain itu, KPK perlu diletakkan bukan di bawah lembaga eksekutif, melainkan sebagai lembaga negara independen agar dapat menjalankan fungsi pemberantasan korupsinya secara maksimal.

\section{Daftar Pustaka}

\section{Buku}

Bungin, Burhan, Metodologi Penelitian Kualitatif: Komunikasi, Ekonomi, dan Kebijakan Publik serta Ilmu-ilmu Sosial Lainnya, Prenada Media Group, Jakarta, 2010.

Fajar, Mukti \& Yulianto Achmad, Dualisme Penelitian Hukum Normatif \& Empiris, Yogyakarta: Pustaka Pelajar, 2013.

Isharyanto, Hukum Kelembagaan Negara (Studi Hukum dan Konstitusi Mengenai Perkembangan Ketatanegaraan Republik Indonesia), Cetakan I, Fakultas Hukum UNS, Surakarta, 2015.

\section{Jurnal/Penelitian}

Bak, Mathias, "Overview of Corruption and Anti-Corruption in Myanmar", Transparency International Helpdesk Answer, 2019.

Chan, Thomas, "Corruption Prevention - The Hong Kong Experience", Resource Material Series No. 56 113th International Training Course Visiting Experts Papers.

Hean, Soh Kee, "Investigation and Prosecution of Corruption Offences", Resource Material Series No. 80 The Twelfth International Training Course on the Criminal Justice Response to Corruption Cisiting Expert's Papers diakses melalui https://www.unafei.or.jp/publications/pdf/RS_No80/No80_ 20VE_Hean2.pdf pada tanggal 14 Oktober 2019

Kapeli, Nur Shafiqa and Nafsiah Mohamed, "Insight of Anti-Corruption Initiatives in Malaysia", Procedia Economics and Finance (31) 2015

Lim, Vincent, "An Overview of Singapore's Anti-Corruption Strategy and The Role of the CPIB in Fighting Corruption", Resource Material Series No. 104, 20th UNAFEI UNCAC Training Programme Cisiting Experts Papers, diakses melalui https://www.unafei.or.jp/publications/pdf/RS_No104/No104_ 18_VE_Lim_1.pdf pada 14 Oktober 2019

Nurtjahjo, Hendra, "Lembaga, Badan, dan Komisi Negara Independen (State Auxiliary Agencies) di Indonesia: Tinjauan Hukum Tata Negara", Jurnal Hukum dan Pembangunan Vol. 35 No. 3 Juli-September 2005 
Siddiquee, Noore Alam, "Approaches to Fighting Corruption and Managing Integrity in Malaysia: A Critical Perspective", Journal of Administrative Science Vol. 8 Issue I, 2011

Suyatmiko, Wawan dan Alvin Nicola, "Inisiatif Penguatan Lembaga Antikorupsi Indonesia: Komisi Pemberantasan Korupsi 2015 - 2019", Transparency International 2019

Quah, Jon S.T., "Anti-Corruption Agencies in Asia Pacific Countries: An Evaluation of their Performance and Challenges", Transparency International 2017, diakses melalui https://www.transparency.org/files/content/feature/2017_ACA_Backg round_Paper.pdf tanggal 9 Oktober 2019.

Wing-Chi, Hui "Combating Corruption: The Hong Kong Experience", Tsinghua China Law Review Vol. 6: 2392014

\section{Internet}

Corruption Perception Index 2018: Statistically Significant Changes https://www.transparency.org/cpi2018 diakses pada tanggal 8 Oktober 2019

Corruption Index Perception 2018: Score Timeseries Since 2012, https://www.transparency.org/cpi2018 diakses pada tanggal 8 Oktober 2019.

\section{Peraturan Perundang-Undangan/Acts/Ordinances}

UU No. 19 Tahun 2019 tentang Perubahan Kedua atas Undang-Undang Nomor 30 Tahun 2002: Tambahan Lembaran Negara Republik Indonesia Nomor 6409

The Anti-Corruption Law (The Pyidaungsu Law No. 3, 2013) Myanmar.

The Anti-Corruption Commission Notification No. 3/2015 Myanmar

Special Committee on Corruption dan Complaints Committee, Malaysia

Act 694 tentang Malaysian Anti-Corruption Commission Act 2009

Prevention of Corruption Act (Chapter 241) Ordinance 39 of 1960 Singapore

Cap. 204 Independent Commission Against Corruption Ordinance, Hong Kong 